BRAVING

THE STREET

\section{Braving the street. The anthropology of homelessness}

\author{
Glasser, Irene y Bridgman, Rae
}

New York, Bergahn Books, 1999.

Por Santiago Bachiller

El objetivo del libro consiste en realizar un estado del arte de la bibliografía antropológica existente sobre quienes se ven forzados a residir en la vía pública. Si bien la obra hace referencia a estudios provenientes de diversas latitudes, se centra en las investigaciones producidas en Estados Unidos de América y Canadá.

Un dilema recurrente en la literatura sobre la materia es cómo nombrar a un problema social tan complejo. Continuamos sin llegar a un acuerdo, por lo cual las definiciones varían enormemente. El modo en que la antropología afronta dicho dilema consiste en privilegiar el punto de vista nativo. Pero dicha opción tampoco resulta satisfactoria en una población que rechaza considerarse a sí misma como "sin hogar”. A su vez, la antropología se caracteriza por reflexionar sobre la dimensión cultural de los fenómenos sociales. Los estudios antropológicos han dejado constancia de cómo las distintas formas de interpretar al fenómeno guardan relación con los múltiples modos en que cada cultura o grupo social concibe el hogar. Por consiguiente, si bien la antropología no resuelve la discusión sobre cómo identificar al fenómeno, resalta la diversidad y aporta elementos para un análisis transnacional.

La obra proporciona abundante información sobre la bibliografía dedicada a los procedimientos empleados para el recuento de personas sin hogar. Se trata de una cues- tión fundamental pues, al igual que ocurre con las definiciones que se adopten, el tipo de metodología incide en la composición y cantidad de personas que se contabilizan. De más está decir que en dichas discusiones subyace una dimensión política que trasciende el plano metodológico.

La literatura dedicada a explicar el sinhogarismo refleja dos lógicas argumentales: a) las estructurales destacan determinados procesos globales como factor desencadenante (la desinstitucionalización psiquiátrica, la gentrificación, la falta de políticas sociales, etc.); b) otros estudios se centran en las limitaciones personales que convierten a determinados sujetos en particularmente vulnerables frente a los riesgos de verse atrapados en la calle (aquí se priorizan las visiones desa囚liatorias y psicopatológicas). Con la pretensión de sintetizar ambas posturas, Glasser y Bridgman reivindican la aspiración holística propia de la antropología. El holismo se equipara con un modelo de explicación ecológico, con una constelación de causas que conducen al sinhogarismo. A pesar de lo expresado por las autoras, entendemos que la particularidad antropológica en los estudios sobre el sinhogarismo no ha consistido en su capacidad de combinar lo estructural con lo individual, sino en añadir la dimensión cultural a tales análisis. Su fuerte tampoco ha sido la determinación de las causas del fenómeno, sino el abordaje de los procesos de adaptación en el contexto de 
calle. El aporte más sustancial consistió en refutar el aislamiento en tanto supuesto central en las caracterizaciones de los sin hogar; para ello, las autoras reflexionan en torno a la vida diaria en la calle así como en las estrategias de supervivencia y adaptación de los sujetos. Asimismo, la obra deja constancia de cómo la antropología ha sido la disciplina que mayor peso le ha otorgado al espacio de residencia como dimensión prioritaria en los procesos de conformación de subjetividades y sociabilidades. De tal modo, una particularidad de los enfoques antropológicos ha residido en privilegiar como eje de análisis a la calle antes que a los servicios sociales para homeless.

La movilidad ha sido una constante en los estudios sobre el sinhogarismo. En la relación entre el espacio de residencia y los patrones de movilidad, las redes sociales de los sin techo han sido otro elemento resaltado por la disciplina. La mayoría de las opciones de subsistencia y adaptación se articulan en torno a redes que se insertan en los territorios de residencia. Es abundante la bibliografía que trata sobre las diversas estrategias de obtención de recursos, las cuales suponen cierto contacto social con quienes disfrutan de un hogar.

Una peculiaridad propia de estos estudios ha consistido en preguntarse por el sentido de comunidad, por los procesos de conformación de un "nosotros" que permite la constitución de grupos de personas sin hogar (la obra suministra abundante información sobre grupos específicos en función de variables como la edad, el género, problemas de adicciones, etc.). Estas investigaciones dan cuenta de los conflictos, expulsiones del territorio, pero también de las alianzas, las diversas formas de cooperación y solidaridad, del esfuerzo por apropiarse y transformar conjunta y temporalmente de un espacio público buscando hacerlo "vivible". En tal sentido, los enfoques que priorizan el aislamiento como factor explicativo pasan de la imagen de personas solitarias a la conformación de grupos que responden a lógicas diametralmente opuestas a las que rigen el conjunto social. En una tradición sociológica marcada por la noción de subclase, se exacerba una racionalidad radicalmente diferente que los ubica en un submundo infranqueable. La antropología discute con tales visiones a partir de las nociones de subcultu- ra, de relativismo, contexto y racionalidad. En tal sentido, se destaca que vivir en la vía pública genera un agotamiento mental por el cual muchos de los comportamientos que parecen patológicos no son causa sino simples estrategias adaptativas para protegerse de los peligros propios del sinhogarismo. Es decir, la racionalidad de los comportamientos solo puede ser comprendida tomando a la calle como contexto espacial que condiciona las representaciones y prácticas de los sujetos.

Braving the street también cita estudios centrados en los programas de lucha contra el sinhogarismo. Se menciona la literatura que apunta a programas específicos, como la promoción de la movilidad de las personas sin hogar o la prevención del fenómeno. La bibliografía subraya que los procesos de reinserción que no contemplen cómo la sociabilidad de esta gente se materializa en redes barriales tienen pocas posibilidades de éxito. La obra también aporta referencias sobre programas que desembocaron en la conformación de cooperativas y movimientos de personas sin hogar. A su vez, la variable espacial emerge en las investigaciones que se preguntan por la estigmatización de los servicios sociales. Esta noción remite al sentido de habitar, el cual es trastrocado tras años de socialización en un territorio degradante. Las permanentes reincidencias dan cuenta de cómo, para quienes llevan años de calle, acabar con el sinhogarismo se equipara con la disrupción de las estrategias de subsistencia y del contacto cotidiano con los conocidos. Así, las políticas de viviendas protegidas deberían contemplar el concepto de hogar que sustentan los sujetos para entender con mayor profundidad los alcances del sinhogarismo. Finalmente, la literatura resalta el potencial de la antropología en lo que respecta a la investigación participativa con personas sin hogar, dando espacio a su voz en el diseño, implementación y evaluación de los programas destinados para estos grupos.

En definitiva, el trabajo de Glasser y Bridgman representa una síntesis indispensable para quienes se encuentren interesados en la búsqueda de bibliografía sobre el sinhogarismo, más aún para aquellos que pretendan priorizar los aportes realizados por la antropología a la literatura sobre la materia. 